\title{
Hypertrophic Pyloric Stenosis
}

National Cancer Institute

\section{Source}

National Cancer Institute. Hypertrophic Pyloric Stenosis. NCI Thesaurus. Code C98952.

An abnormality characterized by thickening of the muscle in the wall of the pylorus. It results in the narrowing of the pyloric channel. The overlying mucosa may appear hypertrophic as well. Clinical signs and symptoms appear early in life and include projectile vomiting and dehydration. 